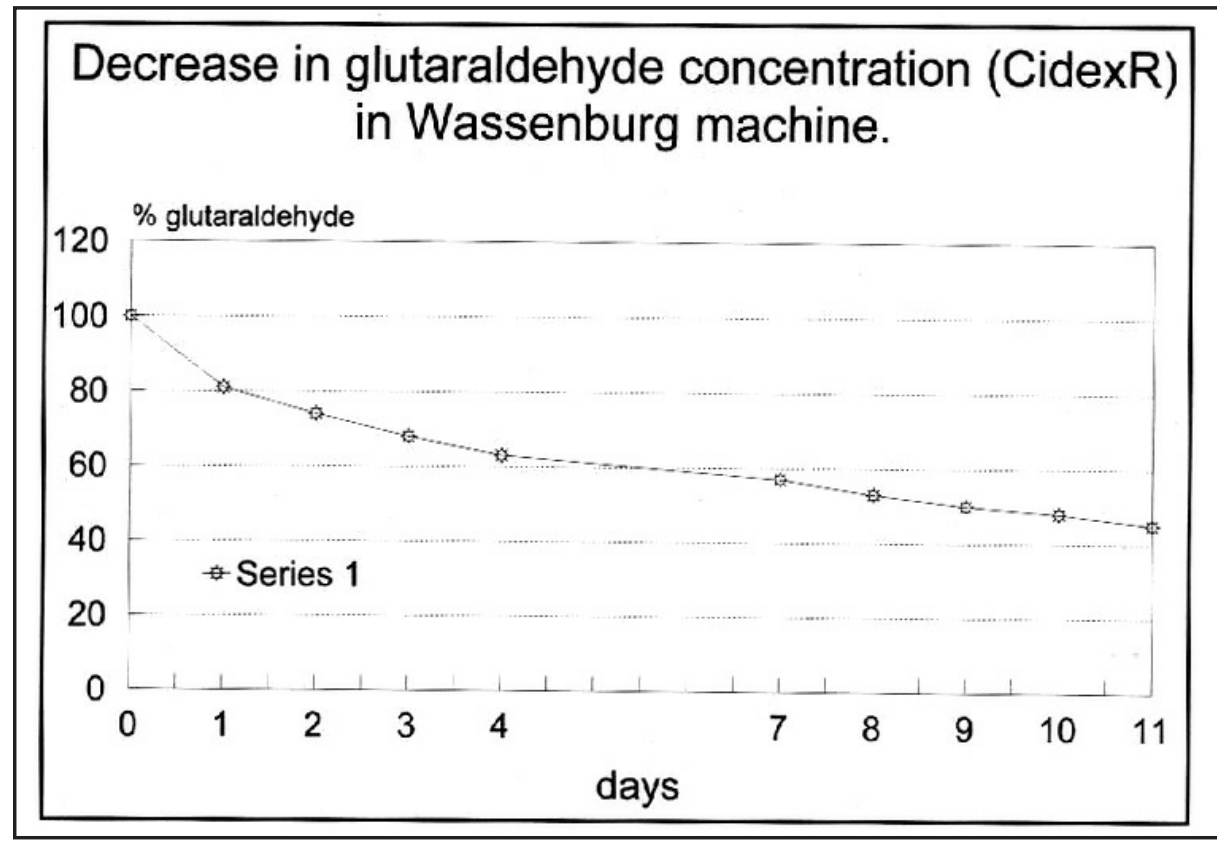

Figure 2. Decrease in glutaralde hyde concentration (CidexR) in Wassenburg machine.

lishment of a biofilm, which can be avoided by disinfection of the machine with a solution of chlorine (250 ppm). We apply chlorine disinfection in our systems every 2 weeks. The water filter is replaced weekly by a sterilized $0.2 \mu \mathrm{m}$ membrane filter.

The literature mentioned in Russell's review, the results from our experiments, and the precautions for recontamination mentioned above made us decide to change the Cidex in the Wassenburg machines every 2 weeks, starting on the first day of the week.

Our investigations showed that every new disinfecting machine that uses glutaraldehyde must be tested and/or validated for daily use.

\section{REFERENCES}

1. Russell AD. Glutaraldehyde: current status and uses. Infect Control Hosp Epidemiol 1994;15:724-733.
2. Meuwissen SGM, Maclaren DM, Rijsberman W, Boshuizen K. Disinfection of a new generation of fibre endoscopes. J Hosp Infect 1983;4:81-84.

H.H.M. Meester A.C. van Loenen, PharmD P.N.F.C. de Goede J.G.M. Koeleman, MD University Hospital Vrije Universiteit Amsterdam, The Netherlands

\title{
Rifampin-Resistant, Isoniazid-Susceptible TB in HIV Patients
}

\section{by Gina Pugliese, RN, MS Medical News Editor}

Dr. Charles Nolan and colleagues from the Seattle-King County Department of Health recently reported acquired rifampin resistance without preexisting isoniazid resistance in three patients with tuberculosis and HIV infection. The patients originally had Mycobacterium tuberculosis strains that were susceptible to isoniazid and rifampin. During treatment (two patients) or after completion of therapy (one patient), active, rifampinresistant, isoniazid-susceptible tuberculosis developed. One patient's isolate subsequently developed isoniazid resistance, also. Studies on the isolates, using restriction fragmentlength polymorphism typing and $r p o B$ gene mutation sequencing, indicted that, in each instance, rifampin resistance arose during therapy by an $r p o B$ gene mutation in the original $M$ tuberculosis isolate.
Using DNA fingerprinting, the researchers established that the development of rifampin resistance in these three HIV-infected patients did not occur by reinfection with a new strain of $M$ tuberculosis, as has been described previously.

From: Nolan CM, Williams DL, Cave MD, et. al. Evolution of rifampin resistance in HIV-associated tuberculosis. Am J Respir Crit Care Med 1995;152:1067-1071. 